\title{
A cross-sectional study of the association between persistent organochlorine pollutants and diabetes Lars Rylander, Anna Rignell-Hydbom and Lars Hagmar*
} \author{
Hospital, SE-221 85 Lund, Sweden \\ Email: Lars Rylander - lars.rylander@med.lu.se; Anna Rignell-Hydbom - anna.rignell-hydbom@med.lu.se; \\ Lars Hagmar* - lars.hagmar@med.lu.se \\ * Corresponding author
}

Address: Division of Occupational and Environmental Medicine and Psychiatric Epidemiology, Department of Laboratory Medicine, University

\begin{abstract}
Background: Experimental evidence supports the hypothesis that persistent organochlorine pollutants (POPs) may cause type 2 diabetes mellitus, whereas there is no fully convincing epidemiological evidence for such an association. In Sweden the most important source of POP exposure is fatty fish. We have assessed the association between serum levels of POPs and prevalence of diabetes in Swedish fishermen and their wives, with high consumption of fatty fish from the Baltic Sea.
\end{abstract}

Methods: In 196 men (median age 60 years) and 184 women (median age 64 years), we analyzed 2,2',4,4',5,5'-hexachlorobiphenyl (CB-I53) and I, I-dichloro-2,2-bis(p-chlorophenyl)-ethylene (p,p'$\mathrm{DDE}$ ) in serum using gas chromatography-mass spectrometry. The participants were asked if they had diabetes and, if so, since which year and about medication and diet. The Odds Ratios (OR) for diabetes with respect to continuous exposure variables were analyzed with logistic regression, adjusting for potential confounders. Moreover trends of diabetes prevalence with respect to trichotomized exposure variables were tested with Jonckheere-Terpstra's test.

Results: Six percent of the men and $5 \%$ of the women had diabetes. After confounder adjustment CB-I53 was significantly associated with diabetes prevalence using both categorized and continuous exposure data (an increase of $100 \mathrm{ng} / \mathrm{g}$ lipid corresponded to an OR of $1.16,95 \%$ confidence interval $[\mathrm{Cl}] \mathrm{I} .03, \mathrm{I} .32, \mathrm{p}=0.03)$. Similar associations were observed for $\mathrm{p}, \mathrm{p}^{\prime}-\mathrm{DDE}$ (an increase of $100 \mathrm{ng} / \mathrm{g}$ lipid corresponded to an OR of I.05, $95 \% \mathrm{Cl}$ I.0I, I.09, $P=0.006$ ). Gender stratified analyses showed among men consistent positive associations with CB-I53, but a more ambiguous pattern with respect to DDE. In contrast, among the women the associations with p,p'DDE were stronger than with CB-I53.

Conclusion: The study provides support that POP exposure might contribute to type 2 diabetes mellitus.

\section{Introduction}

It is widely believed that the increase in incidence of type
2 diabetes mellitus (T2DM) and obesity is the result of a complex interplay between genetic and environmental 
Table I: Characteristics for the 196 men and 184 women from Sweden that participated in the study

\begin{tabular}{|c|c|c|c|c|}
\hline & \multicolumn{2}{|c|}{ Men } & \multicolumn{2}{|c|}{ Women } \\
\hline & \multicolumn{2}{|c|}{ Diabetes } & \multicolumn{2}{|c|}{ Diabetes } \\
\hline & No $(n=184)$ & Yes $(n=12)$ & No $(n=174)$ & Yes $(n=10)$ \\
\hline & $\begin{array}{c}\text { Mean, median } \\
\left(5^{\text {th }}, 95^{\text {th } \%)}\right.\end{array}$ & $\begin{array}{l}\text { Mean, median } \\
\left(5^{\text {th }}, 95^{\text {th } \%)}\right.\end{array}$ & $\begin{array}{c}\text { Mean, median } \\
\left(5^{\text {th }}, 95^{\text {th } \%)}\right.\end{array}$ & $\begin{array}{c}\text { Mean, median } \\
\left(5^{\text {th }}, 95^{\text {th }}\right)\end{array}$ \\
\hline \multicolumn{5}{|l|}{ Age $(y r)$} \\
\hline Current & $\begin{array}{c}60,59 \\
(49,75)\end{array}$ & $\begin{array}{c}60,60 \\
(53,67)\end{array}$ & $\begin{array}{c}63,61 \\
(51,77)\end{array}$ & $\begin{array}{c}64,64 \\
(51,74)\end{array}$ \\
\hline At diagnosis & - & $\begin{array}{c}52,52 \\
(30,62)\end{array}$ & - & $\begin{array}{c}55,56 \\
(45,65)\end{array}$ \\
\hline Time since diagnosis $(y r)$ & - & $\begin{array}{c}9,5 \\
(2,26)\end{array}$ & - & $\begin{array}{l}10,10 \\
(0,27)\end{array}$ \\
\hline \multicolumn{5}{|l|}{ Body Mass Index $\left(\mathrm{kg} / \mathrm{m}^{2}\right)$} \\
\hline Current & $\begin{array}{c}28.6,28.1 \\
(23.5,35.5)\end{array}$ & $\begin{array}{c}29.4,30.1 \\
(22.4,33.3)\end{array}$ & $\begin{array}{c}27.9,27.2 \\
(21.3,35.8)\end{array}$ & $\begin{array}{c}30.4,29.5 \\
(26.6,41.3)\end{array}$ \\
\hline At 25 years of age & $\begin{array}{c}23.4,24.0 \\
(20.0,28.9)\end{array}$ & $\begin{array}{c}26.0,25.4 \\
(21.3,32.6)\end{array}$ & $\begin{array}{c}22.0,22.0 \\
(17.9,26.6)\end{array}$ & $\begin{array}{c}23.0,22.5 \\
(19.7,26.6)\end{array}$ \\
\hline \multicolumn{5}{|l|}{ Exposure (ng/g lipid) } \\
\hline CB- 153 & $\begin{array}{c}430,360 \\
(110,950)\end{array}$ & $\begin{array}{c}670,560 \\
(360,1600)\end{array}$ & $\begin{array}{l}280,240 \\
(94,620)\end{array}$ & $\begin{array}{c}300,230 \\
(110,810)\end{array}$ \\
\hline p,p'-DDE & $\begin{array}{c}800,570 \\
(110,2100)\end{array}$ & $\begin{array}{l}1100,1100 \\
(390,2400)\end{array}$ & $\begin{array}{c}800,590 \\
(100,2300)\end{array}$ & $\begin{array}{l}1600,990 \\
(300,5300)\end{array}$ \\
\hline
\end{tabular}

factors [1]. T2DM is due to resistance to insulin action and a relative deficiency of insulin. Age, obesity, central adiposity, lack of physical activity, dietary glycemic load, as well as certain genotypic variants are the main factors identified as responsible for the disease $[2,3]$.

Exposure to dioxin has been linked to drastic reductions in glucose uptake in guinea pigs, mice and rats, in vivo as well as in vitro [4], leading to speculation that chronic lowlevel exposure to dioxins might be a risk factor for T2DM [5].

Previous epidemiological studies have recently been reviewed [6]. Several studies have linked high dioxin burdens to increased risks of T2DM or modified glucose metabolism [7-10]. A Belgian study published later showed highly significant elevation of serum levels of dioxins and polychlorinated biphenyls (PCBs) among patients with type T2DM [11]. Moreover, also chlorinated insecticides have been associated with T2DM. In a group of pesticide users and an unexposed group, Morgan et al [12] found that subjects with T2DM had higher blood levels of dichlorodiphenyl trichloroethane (DDT) and 1,1dichloro-2,2-bis(p-chlorophenyl)-ethylene (p,p'-DDE), which is the major metabolite of DDT.

A major difficulty in these studies is, however, that exposure occurred sometimes many years before the epidemi- ologic study, which makes it difficult to determine whether the higher serum levels of persistent organochlorine pollutants (POPs) in diabetics truly reflect a higher exposure to these pollutants, which in turn may contribute to diabetogenesis, or whether they are merely the consequence of T2DM-induced metabolic perturbations facilitating the accumulation of these pollutants. Thus, the possibility of a reversed causality cannot be excluded.

In Sweden, consumption of fatty fish from the Baltic Sea, off the Swedish east coast, is the single major exposure source for POPs, and cohorts of professional fishermen and their families from the Swedish east coast have been found to constitute excellent study bases for epidemiological evaluations of human health effects of POPs $[13,14]$. We have chosen to use 2,2',4,4',5, $5^{\prime}$-hexachlorobiphenyl (CB-153) as a biomarker for POP exposure, because it correlates very well $(r \geq 0.98)$ with both total PCB concentration in plasma and serum from Swedish subjects $[15,16]$ and with the 2,3,7,8-tetrachlorodibenzo-p-dioxin (TCDD) toxic equivalent (TEQ) in plasma from PCB $(\mathrm{r}=$ $0.89)$ as well as the total POP derived TEQ $(r=0.74)$ in plasma in American Vietnam veterans [17]. Another relevant exposure biomarker is the anti-androgenic compound $\mathrm{p}, \mathrm{p}^{\prime}$-DDE.

The aim of the present study was to assess the associations between biomarkers for POP and prevalence of diabetes 
in high exposure cohorts of middle-aged and elderly men and women. The results showed an association between the POP markers in serum and prevalence of diabetes.

\section{Methods}

\section{Study population and interview}

Previously established cohorts of professional fishermen and their wives from the Swedish east coast $[14,18]$ were linked to the Swedish Population Register. A postal questionnaire was sent in year 2000 to 1500 fishermen and 1291 fishermen's wives that were born between 1920 and 1954, living in Sweden and still alive at 31 December 1999 [28]. There were 813 men (54\%) and 779 women $(77 \%)$ who responded to the questionnaire. Out of them 510 men and 596 women were positive to participate in future clinical studies. We invited a subset of them to a study mainly focused on bone mineral density [11], but also comprising other potential health effects of POP exposure. The aim was to include 200 men and 200 women in the study, and we consecutively contacted subjects by phone for agreements until enough subjects were recruited. Details of the recruitment process have been given elsewhere [19]. The final study groups comprised 196 men and 184 women.

The participants were interviewed, using a standardized questionnaire. The subjects were asked if they had diabetes and, if so, since which year. Moreover, they were asked if they had per oral antidiabetic drugs, insulin or were on diet. We measured current weight and height. In addition, they were asked about their weight at the age of 25 years. Descriptive data for the participants are shown in Table 1.

Out of the group of 813 men that responded to the questionnaire there were 617 subjects that did not participate in the clinical examination. The non-participants had similar age distribution (median 62 years, range 49-84) as the 196 participants (median 60, range 49-84). In addition, the BMI distributions were also very similar among the non-participants (median $26.5 \mathrm{~kg} / \mathrm{m}^{2}$, range $17.1-$ 39.9) and the participants (median 27.2, range 20.538.5 ). Out of the group of 779 women that responded to the questionnaire there were 595 subjects that did not participate in the clinical examination. There was neither any difference between the non-participating women and the 184 participants with respect to age (median 65 years, range 49-84 versus median 64 years, range 49-83) or BMI (median $26.5 \mathrm{~kg} / \mathrm{m}^{2}$, range 17.1-39.9 versus median 26.2 $\mathrm{kg} / \mathrm{m}^{2}$, range 19.7-38.2).

The study was performed in accordance with the Declaration of Helsinki and approved by The Lund University Ethic's Committee. All participants provided written informed consents.

\section{Blood sampling}

Venous blood samples were drawn between 8.00 and 10.00 A.M, after $12 \mathrm{hr}$ fasting, into sterile Vacutainer glass tubes (BD Vacutainer, Plymouth, UK). Serum was separated by centrifugation (4000 rpm, 10 minutes) and transferred to glass bottles and special tubes. All serum samples were stored at $-80^{\circ} \mathrm{C}$ until analysis.

\section{Determination of $C B-153$ and $p, p^{\prime}-D D E$ in serum}

The analyses were performed applying solid phase extraction using on-column degradation of the lipids and analysis by gas chromatography mass spectrometry as previously described [20-22]. Levels of detection, coefficients of variation and participation in quality control programs have been described in detail elsewhere [22].

\section{Determination of serum lipids by enzymatic methods}

Serum concentrations of triglycerides and cholesterol were determined by enzymatic methods as described elsewhere [22]. The total lipid concentration in serum $(\mathrm{g} / \mathrm{L})$ was calculated by the following equations [23]:

Men: Total $=0.96+1.28 *($ triglycerides + cholesterol $)$

Women: Total $=1.13+1.31 *($ triglycerides + cholesterol $)$.

\section{Statistics}

The effect estimations (odds ratios, OR) between the exposure variables CB-153 and p,p'-DDE, respectively, and diabetes were obtained from logistic regressions. The exposure variables were treated as continuous variables. Due to the high correlation between CB-153 and p,p'DDE (women $r=0.68$; men $r=0.64$ ) these variables were not included in the models simultaneously. As potential confounders we considered gender, current age (as continuous variable) and BMI at 25 years of age (as continuous variable). In addition, the exposure variables were categorized into three equally sized groups. For evaluation whether there were trends in the data with respect to prevalence of diabetes, Jonckheere-Terpstra test (StatXact Statistical Software) was applied. Moreover, separate analyses were performed for men and women. We did also test whether time elapsed since diagnosis of diabetes were correlated (Spearman's correlation test) with the exposure variables and age.

\section{Results}

Twelve of the 196 men (6\%) and 10 of the 184 women $(5 \%)$ had diabetes. Five of the male diabetics had per oral antidiabetic drugs, two had a combination of per oral drugs and insulin, one had insulin only, and the remaining four were only on a diet. The corresponding figures for the female diabetics were four, two, one and three, respectively. 
Table 2: Prevalence of diabetes in relation to tertiles of CB-I53 and p,p'-DDE in serum.

\begin{tabular}{ccc}
\hline Gender & Diabetes & P for trend a \\
\hline Exposure (ng/g lipid) & Yes/No & \\
\hline Male & & \\
CB-153 & & \\
-290 & $0 / 64$ & 0.005 \\
$>290-475$ & $4 / 61$ & \\
$>475$ & $8 / 58$ & 0.04 \\
P,P'-DDE & & \\
-410 & $1 / 63$ & \\
$>410-850$ & $4 / 61$ & \\
$>850$ & $7 / 60$ & \\
Female & & \\
CB-153 & & \\
-180 & $3 / 57$ & \\
$>180-290$ & $4 / 57$ & \\
$>290$ & $3 / 60$ & \\
P,P'-DDE & & \\
-375 & $1 / 59$ & \\
$>375-860$ & $3 / 59$ & \\
$>860$ & $6 / 56$ & \\
\hline
\end{tabular}

a Jonckheere-Terpstra's test

For the whole data set CB-153 was significantly associated with diabetes (an increase of $100 \mathrm{ng} / \mathrm{g}$ lipid corresponded to an OR of $1.16,95 \%$ confidence interval [CI] 1.03, 1.32, $\mathrm{p}=0.03$ ). Among the men the corresponding OR was 1.20 (95\% CI 1.04, 1.39, $\mathrm{p}=0.01)$ and among the women 1.06 $(95 \%$ CI $0.75,1.50, \mathrm{p}=0.74)$. Regarding $\mathrm{p}, \mathrm{p}$-DDE, there was for the whole data set a significant association between exposure and diabetes (an increase of $100 \mathrm{ng} / \mathrm{g}$ lipid corresponded to an OR of 1.05, 95\% CI 1.01, 1.09, $\mathrm{p}=0.006)$. The corresponding ORs were for the men 1.05 $(95 \%$ CI $0.98,1.11, \mathrm{p}=0.14)$ and for the women 1.05 $(95 \%$ CI 1.01, 1.10, p = 0.02). None of the ORs changed more than marginally $(<3 \%)$ by including the potential confounders. Moreover, excluding the two subjects with insulin only therapy changed the risk estimates $<1 \%$.

Using the exposure data categorized into tertiles there were for the whole data set significant positive trends between CB-153 and p,p'-DDE exposure, respectively, and diabetes (Table 2). Among the men significant positive trends between CB-153 exposure and diabetes ( $\mathrm{p}=$ $0.005)$ and between $\mathrm{p}, \mathrm{p}^{\prime}$-DDE exposure and diabetes ( $\mathrm{p}=$ 0.04 ) were observed. Among the women the pattern was very similar regarding $\mathrm{p}, \mathrm{p}^{\prime}$-DDE exposure and diabetes ( $\mathrm{p}$ $=0.07$ ), whereas no such association was observed for the CB-153 exposure.

Time elapsed since diagnosis of diabetes was among the men negatively correlated with CB-153 exposure $\left(r_{s}=\right.$ -
$0.59, \mathrm{p}=0.04)$, whereas it tended to be positively correlated among the women $\left(r_{s}=0.53, p=0.12\right)$.

\section{Discussion}

The main finding of the present study was that diabetics had significantly higher serum levels of both CB-153 and p,p'-DDE than non-diabetic control subjects, using both continuous and categorized exposure data. Gender stratified analyses showed among men consistent positive associations with CB-153, but a more ambiguous pattern with respect to DDE. In contrast, among the women the associations with p,p'-DDE were stronger than with CB153. We have no biological explanation for this gender difference, which might be a random finding considering the relatively small size of the study.

Our overall results are in concordance with a number of previous epidemiological studies showing associations between T2DM and dioxin exposure [7-10], but also with PCB [11] and DDT/DDE [12] exposures. The epidemiological findings have some biological plausibility as TCDD in experimental studies of guinea pigs, mice and rats decreases cellular glucose uptake [4]. Moreover, it has recently been hypothesized that dioxins and dioxin-like PCBs could promote T2DM by interaction with peroxisome proliferators-activated receptor- $\gamma$, a ligand-activated transcription factor controlling lipid metabolism and homeostasis that is linked with T2DM $[5,24]$. There are no experimental data supporting that di-ortho PCB conge- 
ners such as CB-153, will have a diabetogenic effect by themselves, but CB-153 serves as a good proxy marker also for TCDD TEQ and the total POP derived TEQ.

An obvious caveat interpreting the epidemiological crosssectional studies is to know the direction of the causality between POP exposure and T2DM. A reversed causality cannot be excluded, meaning that the disease affects the serum levels of POP. T2DM is associated with a variety of metabolic changes, which quite conceivably could alter the metabolism of POPs. T2DM can alter the pharmacokinetics of some drugs due to e.g. glycosylation of plasma proteins or displacement by increased plasma levels of free fatty acids, or through deteriorated kidney function [25] and also the activity of cytochrome P450 [26]. T2DM is also known to cause a dysregulation of fat metabolism, which in turn might influence the distribution and elimination of lipophilic compounds such as PCBs and dioxins [11]. If diabetics have a slower rate of excretion of TCDD and other POPs, this could account for the observed associations with T2DM [4]. The possibility of a slower elimination of dioxins in T2DM was, however, not supported by a recent study on Vietnam veterans, in whom no difference in TCDD half-life was found between diabetic and non-diabetic patients [27]. Moreover, if T2DM would slow down the excretion of POPs from the body, time elapsed since diagnosis of T2DM should be expected to be positively correlated with CB-153 in serum. Such a correlation was indicated, however not significant, among the women in the present study. On the other hand among the men there was a significant negative correlation between time since T2DM diagnosis and CB-153 in serum, which speaks against that the T2DM would have slowed down their POP excretion.

In the present study we used self-reported diabetes, and had no access to medical records. However, considering the age distribution, time elapsed since diagnosis and that only one man and one woman had insulin as single therapy, we feel convinced that almost all of the patients had a T2DM. Moreover, the prevalence figures in the present study ( $6 \%$ for men and 5\% for men), are well in concordance with was observed in a recent Swedish population based study on similar age groups (about 7\% in men and about $5 \%$ in women) [28]. Moreover, a sensitivity analysis excluding the two diabetic subjects with insulin only therapy showed that the risk estimates were changed with $<1 \%$.

When calculating BMI, we may have slightly underestimated the height at 25 years of age by measuring the current height, but we think that this has only introduced a minor non-differential misclassification.

\section{Conclusion}

This cross-sectional study provides support for the hypothesis that POP exposure might contribute to type 2 diabetes mellitus. Even if we cannot exclude the possibility of a reversed causality, the presently observed negative correlation between time period elapsed since diabetes diagnosis and CB-153 level in serum, speaks for the hypothesis of POP as a risk factor.

\section{List of Abbreviations \\ BMI - Body Mass Index}

CB-153 - 2,2',4,4',5,5'-hexachlorobiphenyl

p,p'-DDE - 1,1-dichloro-2,2-bis(p-chlorophenyl)-ethylene

OR - Odds Ratio

POPs - Persistent Organochlorine Pollutants

TEQ - Toxic Equivalent

T2DM - Type 2 diabetes mellitus

TCDD - 2,3,7,8-tetrachlorodibenzo-p-dioxin

\section{Competing interests}

The author(s) declare that they have no competeting interests.

\section{Authors' contributions}

LH initiated the project. LR and ARH performed the statistical analyses. All authors participated in the design of the study and of writing the manuscript. All authors have read and approved the final manuscript.

\section{Acknowledgements}

Financial support was given by the Swedish Research Council for Medicine, the Swedish Research Council for Environment, Agriculture Sciences and Spatial Planning, the Medical Faculty of Lund University, and Region Skåne funds. We thank Lic med sci Ewa Wallin, Ms Hélène Åkesson and Ms Berit Holmskov for their skilful technical assistance.

\section{References}

I. Schulze MB, Hu FB: Primary prevention of diabetes: what can be done and how much can be prevented? Annu Rev Public Health 2005, 26:445-467.

2. O'Rahilly S: Science, medicine, and the future. Non-insulin dependent diabetes mellitus: the gathering storm. $\mathrm{Br}$ Med J 1997, 3 | 4:955-959.

3. Uusitupa M: Gene-diet interaction in relation to the prevention of obesity and type 2 diabetes: Evidence from the Finnish Diabetes Prevention Study. Nutrition Metab Cardiovasc Dis 2005, 1 5:225-233.

4. Enan E, Matsumura F: 2,3,7,8-tetrachlorodibenzo-p-dioxin (TCDD)-induced changes in glucose transporting activity in guinea pigs, mice and rats in vivo and in vitro. J Biochem Toxicol 1994, 9:97-106. 
5. Remillards RB, Bunce NJ: Linking dioxins to diabetes: epidemiology and biologic plausibility. Environ Health Perspect 2002, I 1 0:853-858.

6. Longnecker MP, Daniels JL: Environmental contaminants as etiologic factors for diabetes. Environ Health Perspect 200I, 109(Suppl 6):87|-6.

7. Pazderova-Vejlupkova J, Lukas E, Nemcova M, Pickova J, Jirasek L: The development and prognosis of chronic intoxication by tetrachlorodibenzo-p-dioxin in men. Arch Environ Health 1981, 36:5-II.

8. Henriksen GL, Ketchum NS, Michalek JE, Swaby JA: Serum dioxin and diabetes mellitus in veterans of Operation Ranch hand. Epidemiology 1997, 8:252-258.

9. Longnecker MP, Michalek JE: Serum dioxin level in relation to diabetes mellitus among Air Force Veterans with background levels of exposure. Epidemiology 2000, I I:44-48.

10. Cramner M, Louie S, Kennedy RH, Kern PA, Fonseca VA: Exposure to 2,3,7,8 tetrachlorodibenzo-p-dioxin (TCDD) is associated with hyperinsulinemia and insulin resistance. Toxicol Sci 2000, 56:43I-436.

II. Fierens S, Mairesse H, Heilier J-F, de Burbure C, Focant J-F, Eppe G, de Pauw E, Bernard A: Dioxin/polychlorinated biphenyl body burden, diabetes and endometriosis: findings in a populationbased study in Belgium. Biomarkers 2003, 8:529-534.

12. Morgan DP, Lin LI, Saikally HH: Morbidity and mortality in workers occupationally exposed to pesticides. Arch Environ Contam Toxicol 1980, 9:349-382.

13. Svensson BG, Nilsson A, Hansson M, Rappe C, Åkesson B, Skerfving $S$ : Exposure to dioxins and dibenzofurans through the consumption of fish. $N$ Engl J Med I99|, 324:8-12.

14. Svensson B-G, Nilsson A, Jonsson E, Schütz A, Åkesson B, Hagmar L: Fish consumption and exposure to persistent organochlorine compounds, mercury, selenium and methylamines in Swedish fishermen. Scand J Work Environ Health 1995, 21:94- 103.

15. Grimvall E, Rylander L, Nilsson-Ehle P, Nilsson U, Strömberg U, Hagmar L, Östman C: Monitoring of polychlorinated biphenyls in human blood plasma with respect to age, lactation and fish consumption; methodology developments. Arch Environ Contam Toxicol 1997, 32:329-336.

16. Glynn AW, Wolk A, Aune M, Atuma S, Zettermark S, Maehle-Schmid M, Darnerud PO, Becker W, Vessby B, Adami HO: Serum concentrations of organochlorines in men: a search for markers of exposure. Sci Total Environ 2000, 263:197-208.

17. Gladen BC, Longnecker MP, Schecter AJ: Correlations among polychlorinated biphenyls, dioxins, and furans in humans. Am $J$ Ind Med 1999, 35: 15-20.

18. Rylander L, Hagmar L: Mortality and cancer incidence among women with a high consumption of fatty fish contaminated with persistent organochlorine compounds. Scand J Work Environ Health 1995, 21:419-426.

19. Wallin E, Rylander L, Jönssson BAG, Lundh $T$, Isaksson A, Hagmar L Exposure to CB-I53 and p,p'-DDE and bone mineral density in middle-aged and elderly men and women. Osteoporosis Int 2005. [epub ahead of print]

20. Richthoff J, Rylander L, Jönsson B, Mårtensson H, Hagmar L, NilssonEhle P, Stridsberg M, Giwercman A: Serum levels of 2,2',4,4',5, ' $^{\prime}$ hexachlorobiphenyl (CB-I53) in relation to markers of reproductive function in young males from the general Swedish population. Environ Health Perspect 2003, I I I:409-13.

21. Rignell-Hydbom A, Rylander L, Giwercman A, Jönsson BAG, NilssonEhle P, Hagmar L: Exposure to CB-153 and p,p'-DDE and male reproductive function. Human Reproduction 2004, 19:2066-2075.

22. Jönsson BAG, Rylander L, Rignell-Hydbom A, Giwercman A, Toft G, Pedersen HS, Ludwicki JK, Zvezday V, Spanò M, Bizzaro D, BonefeldJörgensen EC, Manicardi G-C, Lindh C, Bonde JP, Hagmar L: Determinants of Serum Concentrations of 2,2'4,4'5,5'-hexachlorobiphenyl (CB-I 53) and I, I-dichloro-2,2-bis (p-chlorophenyl)ethylene (p,p'-DDE) in a cross-sectional study of 3161 Men and Women from Greenland, Sweden, Poland and Ukraine. Environmental Health: A Global Access Science Source 2003, 4(I):27.

23. Rylander L, Nilsson-Ehle P, Hagmar L: A simplified precise method for adjusting serum levels of persistent organohalogen pollutants to total serum lipids. Chemosphere in press. 2005 Jul 7
24. Smith SA: Peroxisome proliferator-activated receptors and the regulation of mammalian lipid metabolism. Biochem Soc Transaction 200I, 30: 1086-1090.

25. Gwilt PR, Nahhas RR, Tracewell WG: The effects of diabetes mellitus on pharmacokinetics and pharmacodynamics in humans. Clin Pharmacokinet 199I, 6:477-90.

26. Pass G], Becker W, Kluge R, Linnartz K, Plum L, Giessen K, Joost HG: Effect of hyperinsulinemia and type 2 diabetes-like hyperglycemia on expression of hepatic cytochrome p450 and glutathione $\mathbf{S}$ transferase isoforms in a New Zewaland obesederived mouse backcross population. J Pharmacol Exper Therapeutics 2002, 302:442-450.

27. Michalek J, Ketchum N, Tripathi R: Diabetes mellitus and 2,3,7,8tetrachlorodibenzo-p-dioxin elimination in veterans of Operation Ranch Hand. I Toxicol Environ Health A 2003, 66:2II-22I

28. Eliasson M, Lindahl B, Lundberg, Stegmayr B: No increase in the prevalence of known diabetes between 1986 and 1999 in subjects 25-64 years of age in northern Sweden. Diabetic Medicine 2002, 19:874-880.
Publish with Biomed Central and every scientist can read your work free of charge

"BioMed Central will be the most significant development for disseminating the results of biomedical research in our lifetime. "

Sir Paul Nurse, Cancer Research UK

Your research papers will be:

- available free of charge to the entire biomedical community

- peer reviewed and published immediately upon acceptance

- cited in PubMed and archived on PubMed Central

- yours - you keep the copyright 